\title{
Do aldeamento do Riacho do Mato à Colônia Socorro: defesa de terras e aprendizado político dos indígenas de Pernambuco (1860-1880) ${ }^{1}$
}

\author{
From the Aldeamento of Riacho do Mato to Colônia Socorro: \\ Defense of Lands and Political Learning among \\ Indigenous People of Pernambuco (1860-1880)
}

Mariana Albuquerque Dantas*

\section{RESUMO}

O objetivo do presente artigo é analisar o processo de formação do aldeamento do Riacho do Mato, na década de 1860, a partir das reivindicações de populações indígenas que habitavam a região e que tiveram intensa participação nas revoltas ocorridas no início do século XIX em Pernambuco. A constituição desse aldeamento é compreendida como um importante ganho dos indígenas envolvidos nos conflitos armados iniciados pelas elites. Mesmo com a extinção da aldeia do Riacho do Mato e a criação da Colônia Socorro em seu lugar, os indígenas continuaram lutando pelo acesso às terras. Manejando as legislações e disposições dos governos central e provincial visando às suas próprias necessidades, os indígenas construíram o seu protagonismo na vida política regional e imperial.

Palavras-chave: protagonismo indígena; aldeamento; revoltas.

\section{Abstract}

In this study we intend to analyze the process of formation of the indigenous aldeamento of Riacho do Mato (1860s) based on the claims of indigenous groups in the region, active in the revolts that occurred in the early nineteenth century in Pernambuco (Northeastern Brazil). The constitution of this indigenous settlement constitutes an important gain for the natives involved in armed conflicts initiated by the elites of Pernambuco in the nineteenth century. Even with the replacement of the village of Riacho do Mato by Colônia Socorro, the Indians continued to struggle for access to the lands, using the legislations and provisions of the central and provincial governments aiming at their interests and their needs. In this sense, we see the natives constituting their historical protagonism in regional and imperial political life.

Keywords: indigenous protagonism; settlement; revolts.

\footnotetext{
* Universidade Estadual Vale do Acaraú (UVA), Centro de Ciências Humanas. Sobral, CE, Brasil. m_adantas@yahoo.com.br
} 
A primeira metade do século XIX em Pernambuco foi marcada por intensas disputas em torno de projetos políticos diferentes, que culminaram na eclosão de quatro grandes revoltas armadas: a Insurreição de 1817, a Confederação do Equador (1824), a Guerra dos Cabanos ou Cabanada (18321835) e a Insurreição Praieira (1848-1849). Em todas houve participação de grupos indígenas provenientes da província e de regiões vizinhas (Carvalho, 2002), que perceberam nos conflitos iniciados pelas elites a oportunidade de defender seus anseios e suas necessidades, principalmente no que dizia respeito às terras dos aldeamentos e à sua administração (Dantas, 2015). Ao se envolverem nos violentos embates armados, os indígenas, por meio de suas múltiplas redes de relacionamentos com não índios, conseguiram se articular com líderes rebeldes ou da repressão, participando efetivamente de momentos definidores da história política da região, bem como da construção do Brasil no Oitocentos (Morel, 2003). Essa participação ativa se deu mediante usos da violência política, conceito articulado por Marta Irurozqui para o contexto da Bolívia no século XIX (Irurozqui, 2009, p.11). Apesar dos processos diferentes de constituição dos Estados nacionais brasileiro e boliviano, o uso do conceito no primeiro caso possibilita a compreensão do envolvimento de sujeitos históricos em situação social de subalternos nos complexos processos políticos do período.

Boa parte dos enfrentamentos armados das revoltas ocorreram em uma das grandes regiões produtoras de açúcar da província, a Zona da Mata Sul, que concentrava importantes portos naturais, um grupo significativo e influente de senhores de engenho, e grandes aldeias constituídas ainda no período colonial, como as de Escada e Barreiros. Um espaço específico dessa região, chamado de Riacho do Mato, passou a ser utilizado desde a década de 1830 como refúgio para cabanos, praieiros, pessoas escravizadas, mestiços e indígenas (Silva, 1995, p.72). Na década de 1860, ou seja, anos após o fim da última rebelião do período em Pernambuco, nesse espaço foi constituído um aldeamento composto por índios provenientes da aldeia de Escada e de outras aldeias da região, e também pela população habitante da localidade. O objetivo deste artigo é analisar a criação e a defesa da aldeia do Riacho do Mato em meados do século XIX como um dos desdobramentos da participação dos indígenas nas revoltas mencionadas, envolvimento que proporcionou um aprendizado político para essa população, nos termos de Mônica Dantas (2011). Embora o aldeamento tenha sido extinto e, no mesmo lugar, tenha sido criada a Colônia Socorro para abrigar migrantes das constantes secas em Pernambuco e nas províncias vizinhas, vários indígenas permaneceram 
vivendo na área e continuaram a reivindicar o acesso ao território. Assim, o intuito é analisar como os indígenas que habitavam aquela região desde a década de 1830 lutaram pelo direito à terra por meio da criação do aldeamento e continuaram, posteriormente, reivindicando o usufruto dos lotes concedidos após o processo de extinção daquele espaço.

A constituição do Riacho do Mato foi um feito importante para a população heterogênea que o habitava, já que a defesa de territórios específicos havia sido a principal motivação de indígenas para participarem das revoltas da primeira metade do Oitocentos (Dantas, 2015). A nova aldeia ganha significado ainda mais profundo, pois sua criação se deu num momento em que as autoridades locais e regionais empreendiam grandes esforços políticos e discursivos para extinguir os aldeamentos de Pernambuco (Valle, 1992; Silva, 1995; Ferreira, 2006; Dantas, 2010). Nesse momento, acirravam-se as disputas sobre as categorias sociais e as identidades étnicas relacionadas aos indígenas, uma vez que estavam articuladas ao direito de acesso coletivo às terras dos aldeamentos. Tais disputas estavam conectadas aos conflitos políticos e sociais envolvendo representantes do governo imperial e provincial, grandes proprietários de engenhos, posseiros e indígenas. Concordamos, portanto, com Guillaume Boccara (2001) quando afirma que as disputas em torno de categorias sociais e étnicas estão associadas às tensões políticas e sociais.

Percebendo a potencialidade da legislação indigenista e fundiária do período, por exemplo o Regulamento das Missões de 1845 e a Lei de Terras de 1850, o líder indígena Manuel Valentim, originário da aldeia de Escada, propôs a criação da aldeia do Riacho do Mato dentro dos marcos legais. A depender da situação e das relações entre índios e não índios, as leis citadas permitiam tanto a constituição de novas aldeias, quanto a extinção das mais antigas (Cunha, 1992).

O tortuoso processo de criação da aldeia do Riacho do Mato é também um importante indicativo da inserção complexa dos indígenas na ordem política liberal em construção pelo governo imperial. A compreensão e o uso do aparelho burocrático e político imperial para fazer as demandas (petições e viagens à Corte realizadas por Valentim), bem como a defesa de um espaço coletivo nos moldes das aldeias constituídas no período colonial, apontam para as estratégias indígenas de conciliação entre suas necessidades e o ordenamento liberal oitocentista. Como demonstra Maria Regina Celestino de Almeida (2010, p.141-150), as políticas indígenas eram, então, construídas em um diálogo tensionado com as políticas e ações do Estado imperial. Dessa forma, os indígenas habitantes do Riacho do Mato foram protagonistas do próprio 
processo de demanda por terras, como também participaram ativamente da formação do Estado brasileiro no período.

\section{ADAPTAÇõES ÀS LEIS FUNDIÁRIA E INDIGENISTA}

Com a repressão à Praieira, última rebelião liberal da década de 1840, deu-se a consolidação do projeto conservador na Corte, iniciado com o movimento do Regresso em 1837, como afirma Ilmar Mattos (2009, p.32-33). De acordo com análise de José Murilo de Carvalho, o ano de 1850 foi um marco decisivo, pois nele se reafirmou um Ministério conservador representado pela trindade saquarema, e uma composição na Câmara de Deputados na mesma linha política de maior centralização administrativa. Diante desse contexto parlamentar favorável, o governo se sentiu forte o suficiente para tratar de duas questões centrais ao Império: a mão de obra, sobretudo quanto à problemática do tráfico, e a estrutura fundiária. Foram, assim, instituídos o fim do tráfico de africanos escravizados e a Lei no 601 , também conhecida como Lei de Terras (Carvalho, 2003, p.255-257). Nesse mesmo arcabouço de hegemonia conservadora no governo, foi também promulgado o Regulamento das Missões em 1845 (Sampaio, 2009).

Instrumentalizados em conjunto, a Lei de Terras e o Regulamento de 1845 contribuíram para oficializar e intensificar o processo de extinção dos aldeamentos indígenas pelo Brasil (Cunha, 1992, p.20-21). Na província de Pernambuco, ao final da década de 1870 , já não existia nenhum aldeamento (Valle, 2011, p.296-297). No entanto, esse processo não ocorreu sem a interferência de grupos indígenas, que continuaram lutando pelo acesso coletivo às terras. No Riacho do Mato, os índios que lá permaneceram após os conflitos da primeira metade do Oitocentos e outros provenientes da aldeia de Escada reivindicaram a criação de um novo aldeamento durante a década de 1860 .

Essa aparente contradição (oficialização de um aldeamento enquanto outros eram extintos) contribui para o entendimento de que a situação das aldeias em Pernambuco variava a depender das dinâmicas locais vivenciadas entre índios e não índios e também da aplicação das leis do período relativas às questões fundiária e indígena. A Lei de Terras e o Regulamento das Missões tentavam prever uma maior variedade de situações, tratando igualmente, portanto, da supressão de territórios indígenas e da criação de novos aldeamentos. Isso levava a aplicação dessas legislações a depender das especificidades e das disputas regionais e locais. Assim, enquanto em algumas localidades aldeamentos eram extintos, em outras esses espaços eram constituídos, como 
ocorreu no Rio de Janeiro (Almeida, 2010, p.141-142) e em Pernambuco, com o Riacho do Mato. Embora esses aldeamentos mais recentes também tenham sido suprimidos anos depois, como aconteceu com o do Riacho do Mato em 1873, os indígenas que os habitavam conquistaram importante feito ao estabelecerem um direito específico num contexto de declínio desses espaços. As políticas indígenas, assim, poderiam elaborar novos limites para a aplicação da política indigenista imperial (Almeida, 2010, p.121).

A comissão formada e encarregada de elaborar parecer sobre as aldeias a serem extintas em Pernambuco apontou como uma das suas conclusões o "crescido número de índios existentes nas aldeias", o que poderia colocar em risco o projeto de findar com todos os territórios de uma única vez. A alternativa para lidar com essa situação foi a extinção de alguns aldeamentos, a entrega de lotes aos índios que ainda os habitassem, e a reconfiguração de duas outras aldeias a partir da incorporação dos indígenas que não tivessem recebido lotes dos aldeamentos a serem extintos. ${ }^{2}$

Com base nessas informações, o governo provincial forneceu instruções aos responsáveis pelo processo de extinção, uma das quais a distribuição de lotes de terras aos indígenas e seus descendentes que ainda vivessem no local. Em decreto de 1875, o governo provincial ratificou essa orientação:

nos aldeamentos de que se trata [Riacho do Mato, Barreiros, Ipanema, Brejo dos Padres, Escada e Santa Maria] distribuirá lotes de terras com área de 62.500 braças quadradas ou $302.500 \mathrm{~m}^{2}$ aos índios ou seus sucessores que sejam chefes de família, a de 31.250 braças quadradas ou $151.250 \mathrm{~m}^{2}$ aos solteiros, devendo ser os mesmos lotes mantidos com títulos de propriedade definitiva, caso queiram aí fixar sua residência. ${ }^{3}$

Informados a partir dessas disposições oficiais, os indígenas que continuaram a habitar os territórios dos antigos aldeamentos passaram a reivindicar o direito de manter a posse e o pleno usufruto dos lotes distribuídos na década de 1870. Com isso podemos afirmar que parte da aplicação de leis e orientações elaboradas nos altos escalões da administração imperial, como os ministérios, e no nível provincial, era condicionada pelas variantes locais e regionais relacionadas aos conflitos entre índios e não índios, assim como às articulações indígenas no sentido de se valer das suas próprias intepretações sobre as leis para adaptá-las aos interesses das comunidades. As apropriações feitas pelos indígenas das leis e políticas relativas às suas terras foi comum durante o período colonial na América, como também no período aqui estudado, marcado 
pela proposta liberal de acesso individualizado à terra, processo vivenciado no Brasil e em outras regiões da América Latina, como o México após a Lei Lerdo (1856) (Almeida, 2011, p.122-123; Marino, 2010). A defesa, pelos caminhos legais, da criação de uma aldeia no lugar Riacho do Mato na década de 1860, como se analisará a seguir, demonstra que tal espaço coletivo ainda significava no século XIX algum nível de proteção e garantia do acesso à terra.

\section{Riacho do MATO: GANHO DOS ÍNDIOS E}

\section{DA POPULAÇÃO ENVOLVIDOS NAS REBELIÕES}

A região do Riacho do Mato era conhecida por sua fertilidade, sendo margeada pelo rio Una e por vários riachos, como o Jacuípe-mirim e o Taquara. Durante o inverno, com as chuvas torrenciais, os caminhos se tornavam intransitáveis, causando grandes transtornos aos viajantes mais desavisados. Era, então, uma região propícia ao cultivo de algodão, cana-de-açúcar e café. Dali também se extraíam madeiras e se faziam pequenos roçados. Era uma área importante de circulação entre as províncias vizinhas de Pernambuco e Alagoas, mais especificamente entre as vilas de Água Preta e Jacuípe (Silva, 1995, p.80). Aquele espaço se constituiu como refúgio de cabanos e praieiros, pois muitas pessoas que participaram desses eventos permaneceram morando ali, trabalhando nos engenhos e fazendas e, também, nos seus próprios roçados. É importante ressaltar que nessa região de fronteira se desenvolveu grande parte dos conflitos relacionados às revoltas do período. Foi nesse espaço que desembarcaram as forças de repressão à Insurreição de 1817 e à Confederação de 1824, angariando apoio entre potentados locais e populações indígenas; ali também se enfrentaram cabanos e tropas imperiais, e, anos depois, os praieiros se refugiaram e guerrearam com as forças do governo instituído. Com isso, queremos afirmar que não só a população de pobres livres, libertos e escravizados que já habitava aquela região, mas também a que ali se refugiou, vivenciou experiências singulares nos diferentes contextos de revoltas e guerras.

Concordamos com Mônica Dantas quando afirma que ao participarem dos conflitos armados, ainda que em rebeliões iniciadas pelas elites, aqueles sujeitos históricos em posição social desprivilegiada "aprenderam a lutar, eventualmente até a liderar e, paralelamente, a reinterpretar a experiência da contestação como uma via possível” (Dantas, 2011, p.518-519). A população daquela região, e mais especificamente a do Riacho do Mato, havia passado, portanto, por um aprendizado político que a levou a vivenciar a contestação 
como forma de realizar seus objetivos. Não queremos defender uma análise que enfoque a linearidade dos acontecimentos ocorridos num mesmo espaço, mas afirmar que as vivências bélicas da população pobre habitante daquela área não devem ser menosprezadas, e sim levadas em conta para compreender as suas motivações e estratégias de participação política.

Nesse contexto de experiências e aprendizado político tem-se notícias do índio Manuel Valentim dos Santos, que habitava aquela área desde 1858, tendo sido no ano seguinte reconhecido como o maioral dos cerca de vinte índios do aldeamento de Escada que viviam no Riacho do Mato. De acordo com uma autoridade local, Manuel Valentim participou da Guerra dos Cabanos na década de 1830 e teria fugido para escapar do encarceramento quando Vicente de Paula, conhecido líder cabano, foi preso em 1849. O seu envolvimento na Cabanada deve ter sido intenso, pois Valentim foi chamado por uma das autoridades da região de "um segundo Vicente", o que demonstra também o seu potencial de liderança, igualado ao do grande líder daquela revolta (Silva, 1995, p.90-91).

Valentim ajudou a iniciar um movimento de transferência de muitos índios da aldeia de Escada para o Riacho do Mato em razão das perseguições e invasões de terra que sofriam. Tentando dar início ao processo de reconhecimento do Riacho do Mato como aldeia, Manuel Valentim conseguiu uma autorização do então Diretor Geral dos Índios, José Pedro Veloso da Silveira (um dos líderes da repressão aos praieiros), para permanecer com seus companheiros na região. No entanto, apenas seriam considerados "aldeados" depois de ordem do governo imperial. Não demoraria muito para Valentim fazer requerimentos ao presidente da província e até ao Imperador, no intuito de conseguir o reconhecimento do governo imperial. ${ }^{4}$

Durante a sua estada no Riacho do Mato, Manuel Valentim foi se tornando importante liderança daquela população que pleiteava a demarcação do aldeamento e, por consequência, seu reconhecimento como "aldeados". Afinal, como vimos, a legislação do período continuava garantindo acesso a terras aos indígenas aldeados (Cunha, 1992, p.20-21), o que também significava proteção para sua subsistência frente ao avanço dos canaviais. Ainda que tenha enfrentado muitas discordâncias no interior do grupo e também confrontos com autoridades e vizinhos não indígenas, Valentim e seus aliados conseguiram importantes ganhos na região.

À medida que ali foram se instalando, Valentim e os demais índios criaram outros vínculos com o local. Em 1868 havia várias choupanas e "algumas casas de telha em arruamento" e, segundo o relato de um de seus aliados, os 
índios viviam "honestamente do produto de suas lavouras". ${ }^{5}$ No aldeamento havia engenhos, sendo um deles do índio Manoel Antônio de Araújo. Os índios também se dedicavam ao corte de madeira. ${ }^{6}$

Os indígenas que Valentim liderava eram provenientes de aldeias diferentes. No Riacho do Mato, além da população de pardos, negros e escravizados que habitavam aquela localidade desde a Cabanada, instalaram-se indivíduos da aldeia de Escada, assim como Manuel Valentim, os quais haviam encontrado ali uma alternativa à exploração, invasão e pressão exercidas por proprietários vizinhos ao seu antigo aldeamento. Também havia índios das aldeias do Cocal e de Jacuípe, ambas em Alagoas, para os quais o Riacho do Mato deveria representar um refúgio importante. Segundo o subdelegado da colônia militar Leopoldina, alguns índios do Cocal foram "seduzidos” por Manuel Valentim dos Santos e, por isso, foram encontrados no Riacho do Mato. Ao serem levados de volta para a sua aldeia em Alagoas, logo retornaram ao Riacho do Mato. ${ }^{7}$ Já sobre os índios imigrados de Jacuípe, o Diretor Geral afirmou que viviam sob a proteção de Manuel Valentim. ${ }^{8}$

Não obstante, a liderança de Valentim era questionada com frequência por indígenas descontentes, indicando cisões internas no aldeamento, concretizadas pela divisão entre aldeia de cima e aldeia de baixo. ${ }^{9}$ A documentação analisada não permitiu avançar na investigação sobre as causas desses dissensos internos. Mas, enquanto representante da coletividade, Valentim em conjunto com a mobilização de outros indígenas ajudou a proporcionar ganhos para o grupo, mesmo quando a legitimidade da presença indígena foi questionada por autoridades da região.

Argumentava-se que o lugar poderia se tornar "novo foco de criminosos e malfeitores", tendo em vista os acontecimentos de 1849 e 1850, fazendo referência aos conflitos finais da Praieira, nos quais os índios que reivindicavam terras participaram. Diante de tal quadro, Manuel Valentim e outros 30 índios provenientes da aldeia de Escada se dirigiram ao Diretor Geral dos Índios da província, o Barão dos Guararapes, para intervir no caso e garantir sua permanência no local (Silva, 1995, p.74).

Logo depois disso, percebendo a ausência de retorno do governo provincial, Manuel Valentim recorreu à próxima instância institucional do Império. Viajou ao Rio de Janeiro com outro índio, Jacinto Pereira da Silva, para reivindicar na Corte a transferência dos índios de Escada, onde sofriam perseguições e invasões dos fazendeiros vizinhos. Com isso, eles conseguiram um aviso do Ministério da Agricultura de 14 de setembro de 1861 que determinava a criação do novo aldeamento, mandando medir e demarcar uma porção de 
terreno para os duzentos índios já ali instalados e para os que deveriam chegar da aldeia de Escada. Esse terreno deveria ser medido na proporção de 22.500 braças quadradas para cada família indígena já estabelecida no lugar. A demarcação deveria ter continuidade de acordo com a chegada dos demais índios de Escada até completar uma légua em quadro. Além disso, também se ordenava que fossem distribuídas ferramentas, tais como machados e enxadas para trabalho na lavoura. Deveria ser indicado um Diretor Parcial para o novo aldeamento, sendo este um indivíduo aceito pelos índios. ${ }^{10}$

Esse aviso de 1861 foi acompanhado de outros dois, ambos de 23 de setembro. Como demonstra Sarah Valle, um trata da extinção da aldeia de Escada, motivada pela criação da do Riacho do Mato, e o outro aviso recomenda o reconhecimento dos limites da antiga sesmaria concedida aos índios em Escada e a verificação das posses dos agricultores e senhores de engenho que nela estivessem instalados (Valle, 2011, p.310-311).

É interessante perceber que as terras no Riacho do Mato, de acordo com o primeiro aviso de 1861, foram concedidas em lotes para as famílias indígenas, individualizando o acesso ao território, situação condizente com as novas proposições liberais da Lei de Terras de 1850 e suas regulamentações. Esse foi o mesmo mecanismo utilizado após a extinção dos aldeamentos a partir da década de 1860, para que as famílias pudessem permanecer provendo a sua subsistência nos lotes, descaracterizando o usufruto coletivo do território (Valle, 1992; Silva, 1995; Ferreira, 2006; Dantas, 2010). Ao mesmo tempo, a população ali estabelecida era vista pelo Estado como um grupo, uma coletividade, já que deveria ser administrada por um diretor parcial, tal como dispunha o Regulamento das Missões de $1845 .{ }^{11}$

O reconhecimento da aldeia do Riacho do Mato, conforme o aviso de 1861, ocorreu num momento de intensificação de conflitos e de perspectiva de extinção das aldeias da província, tal como se pretendia fazer com o aldeamento de Escada. A aldeia do Riacho do Mato estava na contracorrente. Sua principal liderança, Manuel Valentim, com domínio dos instrumentos legais e conhecimento das culturas políticas e novas instituições do período, recorreu ao Diretor Geral e ao Imperador para fazer valer suas reivindicações. Baseado nas leis, que ainda garantiam terras para o aldeamento de índios, Manuel Valentim conseguiu aprovação a despeito dos argumentos contrários.

Contudo, os conflitos continuaram no Riacho do Mato e em Escada. Diante da resistência de índios de Escada ao comando exercido por Manuel Valentim, um grupo deles enviou representação ao Diretor Geral no qual informava ser "nociva" a sua transferência para a nova aldeia (Valle, 2011, 
p.307). O Diretor Geral da província, o Barão dos Guararapes, mostrou-se contrário aos avisos citados, argumentando que índios e não índios viviam em conflito pelas terras de Escada, e extingui-la significaria o triunfo dos posseiros. Em sua percepção, o novo aldeamento não traria benefício algum para os índios, já que estariam bem estabelecidos em Escada. A ida de Manuel Valentim à corte, segundo o Diretor Geral, seria um ardil dos posseiros de Escada para conseguir a transferência dos índios para o Riacho do Mato. E a demarcação da sesmaria dos índios já havia sido ordenada, mas não foi realizada por falta de pagamento ao engenheiro responsável (Valle, 2011, p.310-311).

Provavelmente em razão dos argumentos apresentados pelo Diretor Geral e em decorrência de conflitos que envolveram o inspetor de quarteirão Manuel Francisco Jatobá Canuto no final de 1861, o Ministério da Agricultura, em 1862, revogou a remoção dos índios de Escada para o Riacho do Mato e, por consequência, voltou atrás na demarcação das terras. Valentim e outros índios envolvidos foram presos e acusados de desobediência às autoridades, invasão de terras e sedição (Silva, 1995, p.75-76).

Valentim não desistiu e, em 1864, novamente se dirigiu à corte no Rio de Janeiro para esclarecer a situação e reivindicar a delimitação do território da aldeia e a continuidade da remoção oficial dos índios de Escada. O ministro da Agricultura emitiu um aviso no qual ordenou ao presidente da província de Pernambuco que o índio Manuel Valentim permanecesse no Riacho do Mato, "onde tem morada e plantações, e convindo que ali seja garantido em seus direitos, recomendo a Vossa Excelência que o faça persistir naquele lugar até que nova deliberação seja tomada" ${ }^{12}$

Com isso, Valentim conseguiu autorização para permanecer no Riacho do Mato ao lado dos outros indígenas que o acompanhavam, mas as disputas não se resolveriam com facilidade. Nos anos seguintes, a legalidade da existência da aldeia do Riacho do Mato foi questionada pelo Diretor Geral. Ele relembrou, por meio de ofícios produzidos entre os anos de 1865 e 1867, a revogação da transferência dos índios de Escada por ordem do Ministério da Agricultura feita em 1862 (Valle, 2011, p.310-311). Ao escolher enfatizar esse aviso, o Diretor Geral ignorava a ordem de 1864 que mantinha Manuel Valentim instalado na nova aldeia.

Valentim atuou de novo, mesmo diante da solicitação de sua substituição por parte de alguns índios, já que não concordavam com a direção que ele dava ao aldeamento. Valentim também se viu atacado por vizinhos com interesses naquelas terras férteis e que, em parte, recebiam apoio do Diretor Geral dos 
Índios, Lourenço de Sá, o Barão dos Guararapes. Em 1866, Valentim enviou duas petições ao Imperador, descrevendo a situação que se vivia no Riacho.

Na primeira delas, o líder indígena reclamou que as ordens de 1861 e 1864 para que as terras fossem demarcadas não estavam sendo cumpridas e que o referido Diretor Geral estava exercendo pressão para que os índios deixassem suas lavouras e retornassem à aldeia de Escada, onde todo o terreno já estava ocupado por engenhos. Percebendo no Imperador a mais alta instância para realizar essa reivindicação, Valentim pediu proteção e a concretização de suas ordens: "à paternal clemência de Vossa Majestade Imperial recorrem os pobres indígenas para que, dignando-se cobri-los com o manto de sua graça, ordene que sem perda de tempo sejam cumpridas as suas ordens". ${ }^{13}$

Era importante demonstrar obediência para conseguir a mercê do Imperador: "todos os índios se dedicam ao trabalho com respeito, e submissão às leis e autoridades, prestando-se ao serviço público sempre que deles se precisa". ${ }^{14}$

Um mês depois, Valentim enviou nova petição ao Imperador, dessa vez com apoio de índios de outras aldeias. Em conjunto, as aldeias do Riacho do Mato, Barreiros, Ipanema e "Ubá" (Ararobá em Cimbres) pediram a demissão do Diretor Geral, Lourenço de Sá, por estar forçando os índios a saírem de suas terras, enquanto apoiava os posseiros invasores. Segundo Valentim, no Riacho do Mato, os índios haviam "aberto mais clareiras, com grandes sacrifícios plantado suas roças, montado suas engenhocas, levantado seus ranchos", e os posseiros, com violência, tentavam retirá-los das terras já trabalhadas, "desarranjando assim mais de 200 famílias agrícolas", que fazem "todo e qualquer sacrifício para defender o trono de Vossa Majestade Imperial”. Além da demissão do Diretor Geral, os índios de Riacho do Mato também desejavam a demarcação das terras. ${ }^{15}$

Em 1867, a situação do Riacho do Mato ainda não havia sido resolvida. O Diretor Geral, Barão dos Guararapes, respondeu a algumas das acusações de Valentim sobre a administração da aldeia e lembrou que ele fora protagonista de várias turbulências ocorridas na região e que, por isso, o Ministério da Agricultura havia revogado a remoção dos índios de Escada para o Riacho do Mato em 1862. A determinação de Valentim em seu projeto era contestada pelo diretor e por outros índios da localidade. O diretor afirmou que ali, ele "se vai conservando, querendo a todo transe organizar um aldeamento no Riacho do Mato sem estar para isto autorizado". ${ }^{16}$ Os índios contrários à sua liderança argumentaram que Manoel Valentim se fazia senhor do Riacho do 
Mato, colocando nela seus aliados, e abusando da mão de obra dos demais moradores. ${ }^{17}$

Logo em seguida se deu o processo de extinção da aldeia de Escada e medição de lotes no Riacho do Mato para distribuição entre as famílias indígenas (Silva, 1995). Entre 1868 e 1869 se sucederam as disputas sobre os limites dos terrenos ocupados por posseiros e índios que escolheram permanecer em Escada. E para diminuir os conflitos no Riacho do Mato, o Diretor Geral entendia ser necessária a nomeação de um diretor parcial. Mas os conflitos continuaram, até mesmo com a interferência do juiz comissário local em favor dos não índios interessados nas terras da nova aldeia (Valle, 2011, p.314-315).

Valentim defendeu-se das acusações feitas por não índios e índios contrários ao seu comando. Ele pediu auxílio aos seus aliados da região, os quais emitiram atestados sobre a boa conduta dos índios e a obediência prestada ao Imperador (Silva, 1995, p.83). Não satisfeito com o debate sobre sua administração no aldeamento, em nível provincial, viajou uma terceira vez à Corte no Rio de Janeiro. Lá encaminhou uma petição ao Imperador, na qual se queixava das atitudes do juiz interino do Riacho do Mato, Alexandre Falcão, que estaria dando posse a indivíduos não indígenas em terras do aldeamento. Valentim rogava ao Imperador que fosse feita justiça, não reconhecendo os títulos dos posseiros, para "prevenir questões entre os índios, e já para não serem lesados em seus direitos". ${ }^{18}$ Direitos baseados no reconhecimento do primeiro Diretor Geral dos Índios de Pernambuco, José Pedro Veloso da Silveira, e nos avisos de 1861 e 1864 do Ministério da Agricultura. ${ }^{19}$

O estabelecimento e a manutenção da aldeia do Riacho do Mato eram muito criticados pelos proprietários e autoridades locais. Edson Silva chama a atenção para as fontes produzidas durante o processo de 1861 relativas aos conflitos entre índios e um inspetor de quarteirão. Esses conflitos levaram à já citada revogação da remoção dos índios de Escada para o Riacho do Mato em 1862. Nessas fontes, parte das pessoas envolvidas nos conflitos e da população residente na nova aldeia foi descrita como não indígena. Haveria, ao lado de Valentim, "um cabra negro intitulado por Índio", um grupo de "20 a vinte cinco cabras armados entre estes alguns índios”, outros tantos negros, pardos, mamelucos, acaboclados e "cabras". Uma autoridade vizinha explicou que na aldeia viviam "homens de diferentes raças". De acordo com o diretor da Colônia Militar de Pimenteiras, área próxima ao aldeamento, "todos eram supostos índios que se julgavam feridos em seus direitos" (Silva, 1995, p.77-78). 
Esses argumentos demonstram os conflitos em torno da definição das categorias sociais e étnicas, que estavam relacionadas às disputas políticas e sociais, conforme argumentação de Guillaume Boccara (Boccara, 2001). Por isso, num momento de conflitos por terras das aldeias, quando o discurso sobre o desaparecimento dos indígenas mediante mistura estava sendo moldado pelas elites locais, os não indígenas interessados nesses territórios se valiam do questionamento sobre a identidade étnica dos habitantes da nova aldeia. Dessa forma entendemos que, no Riacho do Mato, as classificações étnicas estavam diretamente ligadas às disputas por identidades relacionadas aos conflitos por terras.

Apesar de a argumentação sobre convivência de pessoas consideradas não indígenas ter sido utilizada para deslegitimar as solicitações de reconhecimento do aldeamento, é muito significativo que um índio cabano, como Manuel Valentim dos Santos, tenha escolhido, como outros índios, o lugar do Riacho do Mato para constituir o novo aldeamento. Sobre aquele espaço foram construídos significados e uma relação com a população local importantes para a sua reivindicação de aldeamento indígena. Como já vimos, aquele foi um lugar de convergência de rebeldes ao longo das décadas de 1830 e 1840, dos cabanos, de indivíduos escravizados, dos moradores e de agregados de engenhos transformados em soldados e que desertaram, de grandes proprietários que circularam pela região, de lideranças como Vicente de Paula e de índios de aldeias variadas envolvidos nos conflitos armados.

É de se esperar que a população inserida nos conflitos por terras no Riacho do Mato fosse mestiça e - também podemos afirmar - em grande parte indígena. Os contatos e as relações interétnicas vivenciados ali foram intensificados durante as duas últimas revoltas cujos conflitos ocorreram na região. Mas, além disso, a população indígena deslocada para aquela área, proveniente dos aldeamentos de Escada, Cocal, Jacuípe e Barreiros, já havia passado por profundos processos de reelaborações identitárias e mestiçagens. Conforme vários estudos sobre grupos indígenas aldeados na colônia (Oliveira, 2004; Medeiros, 2011; Lopes, 2005; Almeida, 2013), principalmente a partir da legislação pombalina em meados do século XVIII, as relações interétnicas foram incentivadas por diversos meios, intensificando a presença de não índios dentro das aldeias. Essa foi uma política do governo português para assimilar as populações indígenas, com intuito de transformar seus indivíduos em súditos cristãos do rei, sem distinções em relação aos demais. Embora esse processo tenha acarretado uma série de transformações impostas aos indígenas, reafirmando sua posição de subordinados na hierarquia social da colônia, muitos grupos souberam se 
apropriar de maneira criativa das novas condições e se adaptaram a essa realidade. Afinal, ainda que tivessem seus territórios reduzidos e passassem a assumir várias obrigações, especialmente as relativas ao trabalho, as aldeias representavam garantia de terra e proteção aos indígenas, como bem demonstrou Maria Regina Celestino de Almeida (Almeida, 2013, p.114-115).

Por tudo isso, no século XIX, os indígenas habitantes de aldeamentos coloniais, em sua maioria, não deveriam possuir sinais externos que os diferenciassem em relação à sociedade envolvente. Sob a classificação de "mestiços" utilizada pelas fontes existiriam muitos indivíduos que se percebiam como indígenas lutando pela manutenção de seus aldeamentos. Podemos afirmar, com base nas elaborações teóricas de Max Weber, que traços culturais e até mesmo laços sanguíneos não são os elementos definidores dos grupos étnicos e de suas identidades diferenciadoras. A ação política em favor de interesses comuns exerce papel central na criação e reafirmação do sentimento de comunhão étnica e na criação de identidades coletivas (Weber, 2009). Outro aspecto relevante nesse processo se refere às relações estabelecidas entre diferentes grupos étnicos. De acordo com Fredrik Barth, a formação de grupos étnicos e de suas características diferenciadoras não resulta de isolamento e estagnação, ao contrário, as diferenciações entre os variados grupos são construídas a partir das interações e trocas. Da interação entre membros de diferentes grupos decorrem os critérios de pertencimento ou exclusão, elementos fundantes do sentimento de comunhão criado dentro de uma coletividade. Portanto, a análise relativa aos grupos étnicos se desloca para a abordagem da construção e manutenção das fronteiras sociais entre os grupos, onde ocorrem as relações e/ou conflitos (Barth, 2000, p.26).

Identificar uma população como misturada ou mestiça, para as autoridades locais significava diminuir ou mesmo destituir o direito de grupos sobre o território coletivo das aldeias. Para os sujeitos históricos classificados, ser identificado e se identificar como índio na segunda metade do século XIX ainda significava ter um lugar social e político diferenciado na hierarquia da sociedade imperial que implicava o acesso a direitos específicos, sendo o principal deles a manutenção das terras dos aldeamentos. As disputas por classificações e identidades de grupos indígenas foram uma constante ao longo do século XIX em várias regiões do Brasil, demonstrando os graves problemas relacionados à posse das terras das aldeias vivenciados pelos índios (Almeida, 2008; Silva, 1995; Silva, 2011; Moreira, 2002).

No caso do Riacho do Mato, os indígenas e seu líder Manuel Valentim baseavam suas reivindicações na impossibilidade de continuarem no 
aldeamento de Escada em razão das perseguições que sofriam e na sua instalação de muitos anos no Riacho do Mato, onde já possuíam lavouras e conseguiam prover o seu sustento. A sua presença naquela região fora, aliás, legitimada pelo reconhecimento da Diretoria Geral dos Índios em 1859 e pelos avisos ministeriais de 1861 e 1864. Diante das condições proporcionadas pelas revoltas do período e perseguições sofridas, os índios de Escada e de outras aldeias da região (Cocal, Barreiros e Jacuípe) souberam se adaptar ao novo território e criar novos laços com aquele espaço, conseguindo, até mesmo, respaldo oficial. Reelaboraram suas identidades e agiram politicamente em favor de um objetivo comum constituindo, assim, os sentimentos de pertença e comunhão em torno do novo território.

O líder indígena Manuel Valentim, ainda que não fosse unanimidade entre os índios do Riacho do Mato, havia acumulado experiências de contestação por seu envolvimento na Cabanada e por sua proximidade com o grande líder da época, Vicente de Paula. Torna-se possível inferir que ele construiu interpretações próprias sobre as leis indigenista e fundiária e o novo contexto político, percebendo a possibilidade de reivindicar a constituição de um aldeamento em área tão importante para a população do entorno. Dessa forma, na segunda metade do século XIX, ainda era interessante defender a identidade coletiva indígena, mesmo que essa classificação levasse a problemas sérios, a perseguições, conflitos e desentendimentos. Essa mesma identidade conferia um lugar de fala, uma posição social e uma condição jurídica diferenciados.

\section{COLÔNIA SOCORro: AINDA SOBRE OS INDÍGENAS NO RiACHO DO MATO}

Pouco tempo após a sua criação, o aldeamento do Riacho do Mato foi extinto, acompanhando o processo já em curso na província. Em 1873 foi declarada a sua extinção em conjunto com a do aldeamento de Barreiros, levando à divisão dos territórios em lotes, sendo alguns deles doados às famílias indígenas (Silva, 1995, p.101). Dois anos antes, em 1871, portanto enquanto a aldeia ainda existia legalmente, o Ministério da Agricultura orientou o governo provincial a criar colônias agrícolas para acomodar os imigrantes das recorrentes secas da região. De acordo com essa orientação, o local do Riacho do Mato deveria ser preferencialmente escolhido para a criação da Colônia Socorro, no sentido de aproveitar as terras do aldeamento. O governo da província também sugeriu que outra colônia fosse criada nas "terras públicas" de 
Barreiros, mas lá muitos lotes estavam ocupados por índios, indicando que o local escolhido era o mesmo do aldeamento que existia oficialmente na localidade até 1873 (Freire, 1896, p.36). Seguida a orientação, iniciaram-se os procedimentos para a criação da Colônia Socorro no mesmo local onde havia o aldeamento do Riacho do Mato.

O engenheiro responsável pela criação da Colônia Socorro foi Luiz José da Silva, o mesmo que fez o loteamento das terras dos aldeamentos de Pernambuco após o processo de extinção (Dantas, 2010, p.93). Em abril de 1878 ele seguiu viagem acompanhado de um grande grupo de imigrantes que se transformou em cerca de 4 mil pessoas no momento de fundação da colônia, chegando a um total de 9 mil retirantes poucos meses depois. As terras do local foram descritas pelo engenheiro como "fertilíssimas", entre as quais 47 lotes foram distribuídos inicialmente para as famílias de imigrantes. O engenheiro fez a interessante observação de que 70 lotes "já estavam distribuídos com os índios da antiga aldeia de Escada” (Freire, 1896, p.43-45), ou seja, os que haviam criado o aldeamento do Riacho do Mato na década de 1860 .

Com a chegada inicial de um grupo grande de retirantes de Pernambuco e das províncias vizinhas e com as levas seguintes, as tensões e os conflitos por terra voltaram a se acirrar. Na década de 1870, os indígenas do Riacho do Mato ainda enviavam petições e solicitações às autoridades provinciais com o objetivo de reclamar sobre a invasão dos seus lotes e reivindicar ações do governo. Portanto, os indígenas continuaram a viver nos lotes que lhes haviam sido concedidos e a defender o direito de se manter nessas terras, tal como havia sido assegurado após a extinção da aldeia. Como a índia Curdulina Maria dos Reis que, em 1876, enviou uma petição ao presidente da província, relembrando as ordens dadas na década anterior para medir e demarcar as terras do Riacho do Mato em lotes, dos quais alguns deveriam ser concedidos aos índios para o seu sustento. Curdulina solicitou que, na condição de índia, um dos lotes lhe fosse concedido com o propósito de garantir a alimentação dos seus filhos. ${ }^{20}$ Dois anos depois, Manoel Valentim, em ofício enviado ao presidente da província, informou que os retirantes acomodados nas terras da antiga aldeia estavam se apoderando "violentamente das lavouras" dos indígenas e que, por isso, solicitava a garantia para seu grupo não sofrer mais esbulhos desse tipo. Com o objetivo de reafirmar o seu pleito, Valentim solicitou ao vigário de Escada um atestado de que ainda havia índios vivendo no Riacho do Mato. Ao que o vigário respondeu afirmativamente. ${ }^{21}$

A rápida extinção da Colônia Socorro em 1880, por problemas financeiros e de manutenção pelo governo (Freire, 1896, p.40-50), não significou o fim dos 
conflitos na localidade. As invasões aos lotes concedidos aos índios continuaram sendo realizadas, mas dessa vez pelos proprietários de engenhos vizinhos. Foi esse o caso do índio Manoel Severiano dos Santos, cunhado da índia Curdulina, que solicitou providências ao governador de Pernambuco em relação às investidas do capitão Manoel de Souza Leão, proprietário do Engenho Laranjeira, sobre as terras em que vivia. Manoel Severiano era o tutor de três crianças, seus sobrinhos, filhos portanto de Curdulina e do também índio Luiz José de França. Na condição de tutor, Manoel administrava as terras do seu irmão para prover o sustento dos sobrinhos. ${ }^{22}$ No mesmo ano, a índia Maria Madalena da Conceição enviou uma petição ao governador do Estado de Pernambuco, informando ocupar determinado sítio na localidade do Riacho do Mato há pelo menos 25 anos. A índia solicitou providências do governo em relação aos incêndios e perseguições que vinha sofrendo havia anos, realizados por posseiros vizinhos, o que a impedia de prover o sustento de seus filhos. ${ }^{23}$ Acompanhando a petição de Maria Madalena, segue uma lista nominal, na qual constam cerca de 140 famílias indígenas que ainda habitavam o local Riacho do Mato. ${ }^{24}$

Pelos casos citados, ainda que rapidamente, podemos perceber que os indígenas habitantes do Riacho do Mato conheciam as disposições proferidas pelo governo provincial quando da extinção do aldeamento e, de posse dessas informações, continuaram a lutar pela terra mesmo que de acordo com os novos parâmetros, ou seja, o acesso em lotes. Dessa forma, ao adaptar suas estratégias diante das mudanças legislativas e políticas, entendiam que conseguiriam melhores condições de subsistência para eles próprios e suas famílias.

\section{CONSIDERAÇÕES FINAIS}

As experiências no aldeamento do Riacho do Mato vivenciadas pelos grupos indígenas e a relação construída por eles com esse território específico podem ser entendidas como desdobramentos do seu envolvimento nas revoltas da primeira metade do século XIX. A historicidade dos conflitos armados, das disputas por terras e do uso do espaço como refúgio para cabanos e praieiros ajuda a entender o processo de aprendizado político vivenciado pelos indígenas, bem como justifica a escolha do Riacho do Mato como local para reivindicação de criação de uma nova aldeia. Os indígenas provenientes de diferentes lugares fizeram uso político da violência e da sua experiência de contestação, negociaram e reelaboraram seus campos de apoios mútuos e rivalidades para 
participar da ordem liberal instituída no século XIX a partir das suas próprias necessidades e expectativas. $\mathrm{O}$ ganho situacional e passageiro, representado pela criação da aldeia a partir da apropriação dos meandros das leis imperiais, possibilitou a sobrevivência dos grupos indígenas e não indígenas ali instalados, uma vez que lhes conferiu proteção e alguma autonomia.

Assim, os indígenas habitantes do aldeamento do Riacho do Mato e, posteriormente, os que possuíam o usufruto sobre lotes das terras da Colônia Socorro articularam estratégias para defender seu acesso à terra mediante uma conjunção particular entre disposições e instituições liberais, características do sistema político imperial, e direitos fundiários baseados tanto nas legislações oitocentistas quanto na condição de indígena, categoria e identidade coletiva fundadas e ressignificadas no contexto de Antigo Regime. Por isso, era fundamental ressaltar tal condição nas petições e cartas enviadas às autoridades provinciais e imperiais. A luta pelo reconhecimento e pela oficialização do Riacho do Mato indica a importância desse território específico e também os significados associados ao aldeamento compreendido como um espaço de proteção e acesso à terra no século XIX.

\section{REFERENNCIAS}

ALMEIDA, Maria Regina Celestino de. Índios e mestiços no Rio de Janeiro: significados plurais e cambiantes (séculos XVIII-XIX). Memoria Americana, v.16, n.1, p.1940, 2008.

. Os índios na História do Brasil. Rio de Janeiro: Ed. FGV, 2010.

. Populações indígenas e Estados nacionais latino-americanos: novas abordagens historiográficas. In: AZEVEDO, Cecília; RAMINELLI, Ronald. História das Américas: novas perspectivas. Rio de Janeiro: Ed. FGV, 2011. p.105-133.

Metamorfoses indígenas: identidade e cultura nas aldeias coloniais do Rio de Janeiro. 2.ed. Rio de Janeiro: Ed. FGV, 2013.

BARTH, Fredrik. Os grupos étnicos e suas fronteiras. In: O guru, o iniciador e outras variações antropológicas. Rio de Janeiro: Contra Capa, 2000. p.25-68.

BOCCARA, Guillaume. Mundos nuevos en las fronteras del Nuevo Mundo. Nuevo Mundo Mundos Nuevos. Debates, 2001. Disponível em: https://nuevomundo.revues.org/426\#text; Acesso em: 21 abr. 2017.

CARVALHO, José Murilo de. A construção da ordem: a elite política imperial. Teatro de sombras: a política imperial. Rio de Janeiro: Civilização Brasileira, 2003.

CARVALHO, Marcus J. M. de. Os índios e o ciclo das insurreições liberais em Pernambuco (1817-1848): ideologias e resistência. In: ALMEIDA, Luiz Sávio de; 
GALINDO, Marcos (Org.) Índios do Nordeste: temas e problemas. Maceió: Edufal, 2002. p.67-96.

CUNHA, Manuela Carneiro da (Org.) Legislação indigenista no século XIX: uma compilação: 1808-1889. São Paulo: Ed. Universidade de São Paulo; Comissão Pró-índio de São Paulo, 1992.

DANTAS, Mariana Albuquerque. Dinâmica social e estratégias indígenas: disputas e alianças no aldeamento do Ipanema (1860-1920). Dissertação (Mestrado em História) - Instituto de Ciências Humanas e Filosofia, Universidade Federal Fluminense (UFF). Niterói, 2010.

. Dimensões da participação política indígena na formação do Estado nacional brasileiro: revoltas em Pernambuco e Alagoas (1817-1848). Tese (Doutorado em História) - Instituto de Ciências Humanas e Filosofia, Universidade Federal Fluminense (UFF). Niterói, 2015.

DANTAS, Mônica Duarte. Epílogo. Homens livres pobres e libertos e o aprendizado da política no Império. In: . (Org.) Revoltas, motins, revoluções: homens livres pobres e libertos no Brasil do século XIX. São Paulo: Alameda, 2011. p.511-564.

FERREIRA, Lorena de Mello. São Miguel de Barreiros: uma aldeia indígena no Império. Dissertação (Mestrado em História) - Universidade Federal de Pernambuco (UFPE). Recife, 2006.

FREIRE, A. A. de Luna. Continuação do estudo Colônia Socorro. Revista do Instituto Archeologico e Geographico Pernambucano, n.49, p.31-78, 1896.

IRUROZQUI, Marta. Presentación. Revista de Indias, Dossier: Violencia política en América Latina, siglo XIX, Madrid, v.LXIX, n.246, p.9-16, 2009.

LOPES, Fátima Martins. Em nome da Liberdade: as vilas de índios do Rio Grande do Norte sob o Diretório Pombalino no século XVIII. Tese (Doutorado em História) - Universidade Federal de Pernambuco (UFPE). Recife, 2005.

MARINO, Daniela. Indios, pueblos y la construcción de la nación. La modernización del espacio rural en el centro de México, 1812-1900. In: PANI, Erika (Coord.) Nación, constitución y reforma, 1821-1908. México: CIDE, FCE, Conaculta, INEHRM, Fundación Cultural de la Ciudad de México, 2010. p.163-204.

MATTOS, Ilmar Rohloff de. O gigante e o espelho. In: GRINBERG, Keila; SALLES, Ricardo (Org.) O Brasil Imperial. v.II: 1831-1879. Rio de Janeiro: Civilização Brasileira, 2009. p.13-52.

MEDEIROS, Ricardo Pinto de. Política indigenista do período pombalino e seus reflexos nas capitanias do Norte da América portuguesa. In: OLIVEIRA, João Pacheco de (Org.) A presença indígena no Nordeste: processos de territorialização, modos de reconhecimento e regimes de memória. Rio de Janeiro: Contra Capa, 2011. p.115-144. 
MELlO, José Antonio G. de (Org.) O Diário de Pernambuco e a História Social do Nordeste (1840-1889). v.I. Recife: Diário de Pernambuco, 1975.

MOREIRA, Vânia Maria L. Nem selvagens nem cidadãos: os índios da Vila de Nova Almeida e a usurpação de suas terras durante o século XIX. Dimensões, v.14, p.151$167,2002$.

MOREL, Marco. O período das regências (1831-1840). Rio de Janeiro: Jorge Zahar, 2003.

OLIVEIRA, João Pacheco de. Uma etnologia dos 'índios misturados'? Situação colonial, territorialização e fluxos culturais. In: . (Org.) A viagem da volta: etnicidade, política e reelaboração cultural no Nordeste Indígena. 2.ed. Rio de Janeiro: Contra Capa, 2004. p.13-42.

SAMPAIO, Patrícia. Política indigenista no Brasil imperial. In: GRINBERG, Keila; SALLES, Ricardo (Org.) O Brasil Imperial. v.I: 1808-1831. Rio de Janeiro: Civilização Brasileira, 2009. p.175-206.

SILVA, Edson Hely. O Lugar do Índio. Conflitos, esbulhos de terras e resistência indígena no século XIX: o caso de Escada-PE (1860-1880). Dissertação (Mestrado em História) - Universidade Federal de Pernambuco (UFPE). Recife, 1995.

SILVA, Isabelle Braz P. O relatório provincial de 1863 e a expropriação das terras indígenas. In: OLIVEIRA, João Pacheco de (Org.) A presença indígena no Nordeste: processos de territorialização, modos de reconhecimento e regimes de memória. Rio de Janeiro: Contra Capa, 2011. p.327-345.

VALLE, Sarah Maranhão. A perpetuação da conquista: a destruição das aldeias indígenas em Pernambuco no século XIX. Dissertação (Mestrado em História) - Universidade Federal de Pernambuco (UFPE). Recife, 1992.

. O processo de destruição das aldeias na segunda metade do século XIX. In: OLIVEIRA, João Pacheco de (Org.) A presença indígena no Nordeste: processos de territorialização, modos de reconhecimento e regimes de memória. Rio de Janeiro: Contra Capa, 2011. p.295-326.

WEBER, Marx. Relações comunitárias étnicas. In: Economia e sociedade: fundamentos da sociologia compreensiva. Brasília: Ed. UnB, 2009. p.267-277.

\section{NOTAS}

${ }^{1}$ Agradeço a leitura perspicaz e as sugestões feitas por Maria Regina Celestino de Almeida.

2 "Relatório sobre os aldeamentos de índios na província de Pernambuco" (MELLO, 1975, p.350-351).

${ }^{3}$ Decreto no 273 - Agricultura, comércio e obras públicas - remete cópia das instruções expedidas ao engenheiro Luiz José da Silva para proceder, nos extintos aldeamentos da 
província de Pernambuco à verificação de terrenos pertencentes aos respectivos patrimônios e mais trabalhos que the são correlativos (CUNHA, 1992, p.288).

${ }^{4}$ Arquivo Público Estadual Jordão Emerenciano (Apeje). Série Diversos II, 19. 26/01/1870. Ofício do diretor geral interino dos índios, Francisco Alves Cavalcanti Camboim, para o presidente da província, Frederico de Almeida e Albuquerque. Fl. 154-154v.

${ }^{5}$ Apeje. Série Petições Índios. 22/09/1868. Atestado do capitão reformado do Exército, Trajano Alípio de Carvalho de Mendonça, a pedido de Manuel Valentim dos Santos. Fl.93v.

${ }^{6}$ Apeje. RTP 17. Junho de 1878. Relatório sobre o extinto aldeamento do Riacho do Mato. Fl. 388-388v.

${ }^{7}$ Apeje. Série Petições Índios. 25/12/1865. Atestado do subdelegado da colônia militar Leopoldina, Manoel Cândido Rocha de Andrade. Fl. 81-81v.

${ }^{8}$ Apeje. Série Diversos II, 19. 26/01/1870. Ofício do diretor geral interino dos índios, Francisco Alves Cavalcanti Camboim, para o presidente da província, Frederico de Almeida e Albuquerque. Fl. 154-154v.

${ }^{9}$ Idem.

${ }^{10}$ Apeje. Série Petições Índios. 14/09/1861. Cópia do Ofício do Ministério da Agricultura para o presidente da província de Pernambuco. Fl.74v-75.

${ }^{11}$ Art. $2^{\circ}$ do Decreto ${ }^{\circ} 426$ ou Regulamento acerca das missões de catequese e civilização dos índios (CUNHA, 1992, p.195).

${ }^{12}$ Apeje. Série Petições Î́ndios. 11/03/1864. Aviso do Ministro da Agricultura, Pedro de Alcântara Bellegarde, ao presidente da província de Pernambuco. Fl. 27-27v.

${ }^{13}$ Apeje. Série Petições Índios. Abril de 1866. Petição de Manoel Valentim dos Santos para o imperador dom Pedro II. Fl. 87-87v.

${ }^{14}$ Idem.

${ }^{15}$ Apeje. Série Petições Índios. Maio de 1866. Petição de Manoel Valentim dos Santos para o imperador dom Pedro II. Fl.88-89.

${ }^{16}$ Apeje. Diversos II-19. 01/03/1867. Ofício do diretor geral dos índios, o barão dos Guararapes, para o presidente da província, Francisco de Paula da Silveira Lobo. Diretoria Geral dos Îndios. Fl. 105-105v.

${ }^{17}$ Apeje. Diversos II-19. 25/02/1867. Abaixo-assinado dos índios da aldeia de Escada para o presidente da província, Francisco de Paula da Silveira Lobo. Fl. 106.

${ }^{18}$ Apeje. Série Petições Índios. 12/08/1870. Petição de Manuel Valentim dos Santos para o Imperador, d. Pedro II. Fl.117-118. Grifos meus.

${ }^{19}$ Apeje. Série Petições Índios. 08/07/1870. Petição de Manoel Valentim dos Santos para o Imperador, d. Pedro II. Fl. 116. 
${ }^{20}$ Apeje. Série Petições Índios. Petição de Curdulina Maria dos Reis, índia da aldeia Riacho do Mato, para o presidente da província. Riacho do Mato, 25 de janeiro de 1876. Fl. 122.

${ }^{21}$ Apeje. Série Petições Índios. Petição de Manoel Valentim dos Santos para o presidente da província. Requerimento de atestado de Manoel Valentim dos Santos para o vigário de Escada. Novembro de 1878. Fl. 123-135.

${ }^{22}$ Apeje. Série Petições Índios. Petição de Manoel Severiano dos Santos para o governador do estado. 15/02/1892. Fl. 126-127v.

${ }^{23}$ Apeje. Série Petições Índios. Petição de Maria Madalena da Conceição, índia da extinta aldeia do Riacho do Mato, para o governador do estado. 03/03/1892. Fl. 128-129.

${ }^{24}$ Apeje. Série Petições Índios. Alistamento dos índios do Riacho do Mato. Fl. 130-135.

Artigo recebido em 17 de maio de 2017.

Aprovado em 31 de agosto de 2017.

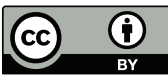

